\title{
Más que palabras: libertad de expresión y discurso de odio en el Sistema Interamericano de Derechos Humanos More than words: freedom of speech and hate speech in the Inter-American Human Rights system
}

\author{
Ana Ximena Jacoby \\ Universidad Autónoma de Campeche \\ ORCID ID 0000-0002-8493-4884 \\ axjacoby@uacam.mx
}

\section{Cita recomendada:}

Jacoby, A. X. (2020). Más que palabras: libertad de expresión y discurso de odio en el Sistema Interamericano de Derechos Humanos. Eunomía. Revista en Cultura de la Legalidad, 18, pp. 148-163.

doi: https://doi.org/10.20318/eunomia.2020.5268

Recibido / received: 09/01/2020

Aceptado / accepted: 12/03/2020

\begin{abstract}
Resumen
El derecho a la libre expresión tiene un alcance sumamente amplio. Incluye, entre otras, la manifestación de ideas y opiniones que otros pueden considerar profundamente ofensivas y perturbadoras. Por su naturaleza radical, este derecho suele entrar en colisión con otros derechos fundamentales, como el derecho a la honra, a la privacidad, al olvido, a la libertad religiosa o con las normas que resguardan la seguridad nacional o la circulación del "discurso de odio". Estas tensiones, que atraviesan al derecho a la libre expresión, quedan frecuentemente manifiestas en fallos y posicionamientos de la Corte Interamericana de Derechos Humanos. El presente trabajo se propone analizar las distintas perspectivas teóricas que subyacen a los posicionamientos de esta Corte en relación al "discurso del odio". Como veremos, en los pronunciamientos de la Corte y los demás órganos que conforman el Sistema Interamericano de Derechos Humanos conviven, dentro de un marco liberal, distintas concepciones que van desde los principios liberales clásicos hasta posturas más cercanas al liberalismo igualitario.
\end{abstract}

\section{Palabras clave}

Discurso de odio, libertad de expresión, Sistema Interamericano de Derechos Humanos 


\begin{abstract}
The freedom of speech has an extremely wide scope. It namely preserves the free expression of ideas and opinions that others might find profoundly offensive and disturbing. Due to its radical nature, this freedom can either collide with other fundamental rights, such as the right to honor, to privacy, to oblivion or to religious freedom, or with certain rules that preserve the national security or the circulation of "hate speech". These tensions crossing the freedom of speech are frequently expressed in judgments and declarations of the Interamerican Court of Human Rights. This work seeks to account for the different theoretical perspectives undermining the arguments presented by this Court regarding "hate speech". As to be seen, different conceptions within a liberal framework coexist in the declarations issued by the Court and rest of bodies that comprise the Interamerican System of Human Rights, ranging from those that follow classic liberal principles to more egalitarian liberalism-oriented positions.
\end{abstract}

\title{
Keywords
}

Hate speech, freedom of speech, Inter-American Human Rights System.

\begin{abstract}
SUMARIO. 1. Introducción. 2. Hacia una definición operativa de discurso de odio. 3. De la palabra a la acción: los marcos regulativos sobre el discurso del odio. 4. El discurso de odio en el Sistema Interamericano de Derechos Humanos. 4.1. La Convención Americana de Derechos Humanos. 4.2. La posición de la Corte Internacional de Derechos Humanos. 4.2.1 La opinión consultiva 5/85. 4.2.2. La última tentación de Cristo. 4.3. Los informes de la RELE. 5. Conclusiones.
\end{abstract}

\section{Introducción}

El derecho a la libertad de expresión tiene un alcance sumamente amplio. Incluye, entre otras, la manifestación de ideas y opiniones que otros pueden considerar profundamente ofensivas y perturbadoras ${ }^{1}$. Sin embargo, existe una preocupación creciente por cierto tipo de expresiones públicas, que además de resultar ofensivas 0 perturbadoras, tienen un efecto nocivo para la convivencia democrática. Estas manifestaciones, a las que se suele denominar genéricamente "discursos de odio», contribuyen a estigmatizar o incitan a la violencia contra determinados grupos sociales.

Este tipo de expresiones se presentan en el discurso público con distintos matices que van desde el discurso hostigador, al discurso discriminatorio y al discurso de odio ${ }^{2}$. Dentro del derecho internacional, existe un consenso en que no todas estas manifestaciones deben ser prohibidas y que la prohibición de estos discursos debe ser antes la excepción que la norma. Hasta aquí llegan los consensos, que son mínimos. Pero incluso al interior de estos consensos existe un amplio abanico de

\footnotetext{
1 Sentencia del Tribunal Europeo de Derechos Humanos (TEDH), caso Handyside v. Reino Unido, de 7 de diciembre de 1976.

2 Retomando la propuesta de Torres y Tarrico, nos referiremos como «discursos de odio» en plural para hacer referencia al discurso genérico, compuesto por otros discursos específicos que pueden clasificarse en función del daño que generan. Dentro de este discurso genérico, encontramos el «discurso hostigador», que refiere las prácticas discursivas sistemáticas realizadas con la intención de impedir o limitar el uso de la palabra en el espacio público; los «discursos discriminatorios», que pretenden que una persona o grupo sean excluidas, segregadas o imposibilitadas de ejercer sus derechos y el «discurso del odio» en singular, que refiere a las prácticas enunciativas que incitan a la comisión de actos violentos, que atentan contra la vida y la seguridad de una persona o grupo de personas (2019, p. 7).
} 
opciones e interpretaciones a la hora de regular, restringir o prohibir su circulación, en función de criterios que están en tensión.

La tensión que recorre la relación entre libertad de expresión y el discurso de odio ha sido objeto de numerosos debates, tanto en el ámbito académico como el jurídico. Podríamos agrupar buena parte de estos debates en dos grandes grupos. EI primero tiene que ver con qué tipo de discursos son los que pueden ser considerados discurso de odio. El segundo se relaciona al modo en que debe regularse la circulación de estos discursos.

Estos dos debates, ofrecerán las coordenadas para organizar los siguientes dos apartados de nuestra exposición. Una vez definido el discurso de odio y descritas las distintas posiciones respecto a su regulación, abordaremos el objeto de nuestro artículo, que es el posicionamiento de la Corte Interamericana de Derechos Humanos (Corte IDH) y de los demás órganos que conforman el Sistema Interamericano de Derechos Humanos (SIDH) en relación al discurso del odio.

\section{Hacia una definición operativa de discurso de odio}

Una primera dificultad que nos encontramos a la hora de definir el discurso de odio, es que en el derecho internacional no existe una definición universalmente aceptada. Desde una perspectiva amplia, pueden considerarse como discurso de odio

todas las formas de expresión que diseminen, inciten, promuevan o justifiquen el odio racial, la xenofobia, el antisemitismo u otras formas de odio basadas en la intolerancia, incluyendo la intolerancia expresada por el nacionalismo agresivo y el etnocentrismo, la discriminación y hostilidad hacia las minorías, migrantes y las personas nacidas de la inmigración (Comité de Ministros Consejo de Europa [CMCE], 1997)

Por su parte, un informe reciente de la Organización de las Naciones Unidas para la Educación, la Ciencia y la Cultura (UNESCO) que analiza distintas definiciones de discurso de odio en el derecho internacional, ofrece una definición más acotada, que circunscribe el concepto a

expresiones a favor de la incitación a hacer daño (particularmente a la discriminación, hostilidad o violencia) con base en la identificación de la víctima como perteneciente a determinado grupo social o demográfico. Puede incluir, entre otros, discursos que incitan, amenazan o motivan a cometer actos de violencia. No obstante, para algunos el concepto se extiende también a las expresiones que alimentan un ambiente de prejuicio e intolerancia en el entendido de que tal ambiente puede incentivar la discriminación, hostilidad y ataques violentos dirigidos a ciertas personas (UNESCO, 2015, p. 10-11).

Estas definiciones contrastan, por lo menos, en dos puntos cruciales. El primero tiene que ver con el destinatario del discurso de odio. Mientras que la definición de UNESCO refiere a "un determinado grupo social o demográfico», la postura retomada por el Tribunal Europeo de Derechos Humanos (TEDH) supone que la agresión debe ir dirigida específicamente a una minoría. Al limitar los discursos de odio a un grupo subalterno, la segunda definición cierra la puerta al mal uso que pueden hacer funcionarios públicos del marco legal sobre discurso de odio para censurar voces críticas o para evitar polémicas como la del el ex Alcalde Giuliani en Nueva York, que pretendía definir como discursos de odio los comentarios negativos hacia la policía (Kaufman, 2015, p. 17).

La segunda diferencia entre ambas definiciones refiere al tipo de acciones contempladas en la definición de discurso de odio. Mientras que la postura citada por 
el TEDH refiere a «todas las formas de expresión que diseminen, inciten, promuevan o justifiquen» el odio, la definición de UNESCO limita el discurso de odio a la «incitación a hacer daño», aun cuando aclara que en definiciones más amplias refiere a «expresiones que alimentan un ambiente de prejuicio e intolerancia». Contrastando ambas definiciones, podemos observar que existe una concepción amplia del discurso de odio, en el que se incluyen todas las «expresiones que alimentan un ambiente de prejuicio e intolerancia» y una concepción más estrecha de quienes lo limitan a la incitación a hacer daño. Cada una de estas definiciones, se corresponde, a su vez a un modelo diferente de regulación del discurso de odio.

\section{De la palabra a la acción: los marcos regulativos del discurso de odio}

La definición más estrecha de discurso de odio como aquel que incita a hacer daño se corresponde, en buena medida, con el modelo de regulación de los Estados Unidos. Este modelo se caracteriza por una protección amplia del derecho a la libre expresión. Su principio medular, que en términos legales descansa sobre la Primera Enmienda, es que el Estado no puede restringir una idea en función de su contenido, incluso cuando éste resulte ofensivo o erróneo, y que las únicas expresiones que pueden ser limitadas son aquellas que puedan producir un daño a otros.

Retomando los argumentos de Sunstein (1993, pp. 163-186) y Massaro (1991, p. 221), Alcácer Guirao sostiene que en el modelo estadounidense

todo discurso extremista, racista, xenófobo o incitador del odio ha de incardinarse bajo el ámbito del discurso político, o del discurso sobre asuntos con relevancia pública, recibiendo, por tanto, la consideración de high value speech y, con ello, la máxima protección que ofrece la Primera Enmienda. [...] Además, toda eventual regulación del discurso del odio -como las existentes en el modelo europeo-, en la medida en que presupone la prohibición de un determinado contenido del discurso dirigido, por lo general, contra grupos sociales específicos, habría de calificarse como basado en un determinado punto de vista [viewpoint-based], infringiéndose con ello el principio de absoluta neutralidad del Estado sobre las convicciones morales y políticas (Alcácer Guirao, 2015, pp. 61-62).

La postura estadounidense quedó plasmada durante la primera mitad del siglo XX en fallos de la Suprema Corte de los Estados Unidos como el caso Chaplinsky v. New Hampshire de 1942 sobre unos Testigos de Jehová que habían insultado a unos oficiales públicos y en el que se establecía que se podían determinar restricciones a la expresión era cuando ésta generaba un «peligro claro y presente». Como señala Rodríguez Zepeda, su vigencia argumentativa terminó de facto en 1969 cuando se estableció, en el marco del caso Brandenburg v. Ohio, que la expresión sólo se puede limitar cuando produzca «acción ilegal inminente» (Rodríguez Zepeda, 2018, p. 39).

En términos teóricos, la prohibición de regulaciones motivadas en el contenido suele asociarse a una visión liberal clásica, tributaria de Stuart Mill (1991), que procura proteger a los ciudadanos del abuso del Estado, identificado como principal fuente de amenazas a la libertad individual.

Este estándar de interpretación constitucional ha sido objeto de críticas e intensos debates. Unas de las primeras objeciones en este sentido provienen de dos autoras que mostraban cómo la libertad de expresión estaba soportada por profundas desigualdades de género (MacKinnon, 1987 y 1993) y raciales (Matsuda, 1993) y proponían limitar el alcance de la Primera Enmienda para regular la libre circulación de la pornografía y de los discursos de odio racial, respectivamente. Sunstein (1993) coincide en que la Primera Enmienda está siendo utilizada para proteger discursos que no deben de ser protegidos, como el discurso difamatorio, ciertas formas de 
pornografía, los discursos que invaden el ámbito privado y el discurso del odio, mientas que ignora a las víctimas genuinas de la difamación. Siguiendo los argumentos de James Madison, sostiene que muchos de los actuales intérpretes de la Primera Enmienda han perdido de vista la racionalidad primaria de la libertad de expresión, que es el "gobierno mediante la discusión» y que una característica distintiva del republicanismo estadounidense es su receptividad al desacuerdo y a la heterogeneidad, más que el temor a los mismos. Consecuentemente, considera que el discurso político debería ser promovido, dado que es esencial para el funcionamiento democrático, mientras que otras formas de discurso no político no deberían ser tan protegidas cuando entran en conflicto con otros intereses y derechos (Sunstein, 1993). Con un argumento afín, Owen Fiss sostiene que si

la libertad de expresión posee tanto valor en la Constitución [...] no es porque es una forma de auto-expresión o auto-realización, sino más bien porque es esencial para la autodeterminación colectiva [...] La libertad a la que el Estado está convocado a promover es una libertad pública (Fiss, 1996, p. 2).

También Waldron mantiene una postura favorable a la censura de los discursos de odio, argumentando que la difamación de grupos minoritarios afecta un bien público que merece ser protegido: la inclusión básica de todos los miembros de la sociedad. Según el autor, estos discursos denigran y estigmatizan a grupos minoritarios, afectando su dignidad y enviando dos tipos de mensajes implícitos. El primero, se dirige a la comunidad denigrada y tiene la función de denigrarlos y hacerles saber que pueden esperar enfrentarse a la humillación y la discriminación al salir de su casa. El segundo mensaje se dirige a quienes sostienen puntos de vista similares, para hacerles saber que no están solos (Waldron, 2012, pp. 57-58).

En el contexto de nuestro trabajo, nos interesa retomar asimismo la postura de Dworkin (1996 y 2000), que -a diferencia de los autores citados anteriormentedefiende la prohibición absoluta de la censura. Desde una postura más cercana al liberalismo igualitario, el autor procura ir más allá de la «tradición de la Primera Enmienda», la cual descansa en una lectura liberal clásica, y por tanto, meramente abstencionista, sobre el Estado. Desde la perspectiva de Dworkin, es importante que existan barreras infranqueables a la intervención estatal. Sin embargo, agrega que una comunidad democrática debe ser una comunidad igualitaria, en la cual la libertad de expresión sería "una garantía básica para el acceso a la expresión y neutralización de influencia desmedidas resultante de fuentes injustas de desigualdad económica o de poder social. Para ello juega un rol crucial el Estado, como instancia de distribución de recursos materiales y otras oportunidades necesarias la promoción de un sistema igualitario"(Dworkin, 1996, p. 238).

Estas propuestas de interpretación de la Primera Enmienda se enmarcan en debates y en proyectos diferentes. Sin embargo, comparten algunos principios comunes. En primer lugar, procuran hacer una lectura de la Primera Enmienda que vaya más allá de la postura liberal clásica del abstencionismo estatal. En segundo lugar, proponen ponderar distintos valores, derechos y principios junto con el de la libertad individual. En tercer lugar, sus argumentos se sostienen sobre una concepción más densa del interés público y los derechos colectivos, considerados tanto o más importantes que el los intereses y derechos del individuo.

Los principios que acabamos de enunciar se acercan más al modelo de regulación del discurso del odio que predomina en buena parte de los convenios internacionales sobre derechos humanos, en la mayor parte de Europa y en otras democracias occidentales como las de Argentina, Japón, Canadá, Colombia y México, entre otras. Gran parte de la literatura se refiere a este modelo como el 
«modelo europeo» (Rosales Roa, 2018; Rodríguez Zepeda, 2018; Valero Heredia, 2017; Colli, 2015a y 2015b; Alcácer Guirao, 2015, entre otros), aun cuando autores como Bustos Gisbert (2015) o Teruel Lozano (2019) observan que esta descripción solo aplica para algunos Estados del continente ${ }^{3}$. Haciendo esta salvedad, respetaremos esta denominación ampliamente aceptada, porque fue en buena medida la experiencia histórica europea y «la experiencia constitucional y legal europea de la segunda mitad del siglo $X X$ la que ha forjado los pilares axiológicos y exegéticos de este modelo» (Rodríguez Zepeda, 2018, p. 43).

Los orígenes históricos de este modelo se suelen asociar a experiencia del nazismo y a la noción de «democracia militante» propuesta por Loewenstein, que supone que las democracias tienen derecho a combatir activamente -incluso mediante la restricción de derechos fundamentales- los movimientos orientados a subvertirla (Esquivel Alonso, 2016, p. 5; Alcácer Guirao, 2015, p. 76). Frente a la lógica abstencionista predominante en los Estados Unidos, centrada en el concepto de «libre mercado de ideas», en el contexto europeo se espera una adhesión de los ciudadanos al ordenamiento jurídico y a sus valores y un rol activo del Estado para promover la igualdad sustantiva y la dignidad de todas las personas (Esquivel Alonso, 2016; Rosales Roa, 2018).

Según la definición del propio TEDH, el discurso de odio hace referencia a «todas las formas de expresión que propaguen, inciten, promuevan o justifiquen el odio basado en la intolerancia». Teruel Lozano destaca los siguientes elementos en esta definición: a) Un discurso en clave excluyente contra un grupo discriminado; b) presencia de un elemento ofensivo mediante expresiones insultantes, vejatorias, humillantes, amenazantes, provocadoras de la comisión de hostilidad, violencia o discriminación contra un grupo o sus miembros; c) existencia de una intención directa en ofender (humillar, insultar, entre otros verbos rectores) y una motivación concreta al actuar por razón de esa intolerancia (Teruel Lozano, 2019, p. 21).

Retomando el argumento de Rodríguez Zepeda podemos sostener que el modelo europeo parte, al menos, de dos supuestos básicos. El primero es que existe un continuum entre la emisión del discurso y las conductas y «pasos al acto» en materia de daño a derechos. Por esta razón, la limitación al discurso significa, de manera directa, una forma de protección de esos derechos fundamentales (Rodríguez Zepeda, 2018, pp. 46-47). El segundo supuesto es que la libertad de expresión debe protegerse conforme a un equilibrio ponderado con otros derechos fundamentales y con otros valores públicos (Rodríguez Zepeda, 2018, p. 46; Colli Ek, 2014, pp. 83-86). Para lograr este equilibrio, este modelo contempla posibles restricciones a la circulación y sanciones de distinto orden para los discursos que se consideran dañinos tanto para la integridad de ciertos grupos sociales como para ciertos valores sociales primarios como la paz o la convivencia social (Rodríguez Zepeda, 2018, p. 37).

Las justificaciones para limitar y sancionar la circulación de ciertos discursos varían en función de las distintas legislaciones nacionales. En el caso de Alemania, por ejemplo, su Carta Magna establece la inviolabilidad de la dignidad humana como su valor supremo, y expresamente limita la libertad de expresión a la medida necesaria para proteger a los jóvenes y el derecho al honor personal. Otro marco jurídico que limita la circulación y penaliza el discurso de odio es el de Canadá. En el

\footnotetext{
${ }^{3}$ Según Teruel Lozano, ordenamientos jurídicos como el español y el italiano no pueden equipararse ni al modelo «tolerante» norteamericano ni al modelo «intransigente» europeo. Por el contrario, el autor caracteriza el modelo español como abierto y personalista $(2019$, p. 21). En relación a esta clasificación, ver asimismo Revenga Sánchez (2015).
} 
fallo de un sonado caso de antisemitismo ${ }^{4}$, la Suprema Corte puso énfasis en «el compromiso de la Constitución canadiense con la diversidad multicultural, la identidad de grupo, la dignidad humana y la igualdad». Con base en estos valores, el Máximo Tribunal adoptó un enfoque matizado concebido para armonizar estos valores con aquellos arraigados en la libertad de expresión, concluyendo que la propaganda del odio como la promovida por Keegstra no justificaba ser protegida, ya que su principal efecto era socavar el respeto mutuo entre los diversos grupos raciales, religiosos y culturales en Canadá más que promover necesidades o valores genuinos de expresión (Rosenfeld, 2005, p. 173).

Una vez esbozados estos dos modelos y descriptos algunos de los principios sobre los que reposan, analizaremos cómo se ven reflejados en el marco del Sistema Interamericano de Derechos Humanos.

\section{El discurso de odio en el Sistema Interamericano de Derechos Humanos}

Llegados a este punto, nos interesa introducir el objeto de análisis de nuestro artículo, que son las concepciones predominantes en el Sistema Interamericano de Derechos Humanos en relación a esta tensión que estamos describiendo. ¿Se acercan los principios interpretativos de la Corte y los demás órganos del SIDH más al modelo estadounidense o al europeo?

La respuesta a este interrogante no es simple por una razón: la Corte IDH no se ha manifestado abiertamente respecto al discurso de odio, sino más bien de manera tangencial. Así lo sostiene un documento de la Relatoría Especial para la Libertad de Expresión de la OEA (RELE-OEA), según el cual:

Los lineamientos básicos que definen las expresiones de odio de acuerdo con el artículo 13(5), a diferencia de las disposiciones similares que se encuentran en los tratados internacionales y en la legislación nacional, aún no han sido interpretados ni desarrollados en profundidad por la Corte Interamericana o la Comisión Interamericana (RELE-OEA, 2004, p. 2).

En este mismo sentido, Rosales Roa observa que el SIDH «a diferencia de otros sistemas, no reporta un desarrollo claro y propio del tema» (Rosales Roa, 2018, p. 9).

Es por ello que basaremos nuestra argumentación en los pronunciamientos más relevantes del SIDH en relación al discurso del odio a través de sus principales órganos -la Comisión Interamericana de Derechos Humanos (CIDH) y la Relatoría Especial para la Libertad de Expresión (RELE) - y en una exégesis de otros fallos y opiniones consultivas de la Corte IDH, que pueden echar luz sobre nuestra pregunta.

\subsection{La Convención Americana de Derechos Humanos}

Para comenzar la argumentación de manera ordenada, empezaremos describiendo el marco legal en el que se encuadra el debate sobre el discurso del odio en la región. La referencia explícita al tema la encontramos en el artículo 13 de la Convención Americana de Derechos Humanos (CADH), que garantiza a todas las personas el derecho a «buscar, recibir y difundir informaciones e ideas de toda índole».

Dos referencias complementarias para la interpretación del discurso de odio aparecen en los artículos 13.2 y 13.5. El primero prohíbe la censura previa y habilita,

\footnotetext{
${ }^{4}$ Sentencia de la Corte Suprema de Canadá, caso Regina v. Keegstra, de 13 de diciembre de 1990.
} 
en cambio, un régimen de responsabilidades ulteriores en situaciones específicamente delimitadas y ajustándose a las siguientes condiciones: (a) las limitaciones deben establecerse mediante leyes redactadas de manera clara y precisa; (b) las limitaciones deben estar orientadas al logro de los objetivos imperiosos autorizados por la Convención Americana; y (c) las limitaciones deben ser necesarias en una sociedad democrática para el logro del objetivo que persiguen, estrictamente proporcionales a la finalidad que buscan, e idóneas para lograr dicho objetivo. Este artículo limita el alcance de la regulación en materia de discursos de odio para aquellos discursos que no incitan abiertamente a la violencia. Así lo sostenía el Relator para la Libertad de Expresión, Eduardo Bertoni, para quien

otras expresiones o comentarios intolerantes que no constituyan estrictamente «incitación a la violencia» pueden ser sujetos al establecimiento de responsabilidades ulteriores para garantizar los derechos a la dignidad y no discriminación de un grupo particular de la sociedad (RELE-OEA, 2015). el cual

La única referencia explícita al discurso de odio la ofrece el artículo 13.5, según

Estará prohibida por la ley toda propaganda en favor de la guerra y toda apología del odio nacional, racial o religioso que constituyan incitaciones a la violencia o cualquier otra acción ilegal similar contra cualquier persona o grupo de personas, por ningún motivo, inclusive los de raza, color, religión, idioma u origen nacional.

Aunque la prescripción del artículo 13.5 parece concluyente, su interpretación ha dado lugar a un extenso debate sobre si las expresiones de odio deben censurarse o someterse a un régimen de responsabilidades ulteriores. Autores como Faúndez Ledesma entiendan que puede existir una franja de «discursos prohibidos», basándose en lo que establece el artículo 13.5 de la CADH y el artículo 20.2 del Pacto Internacional de Derechos Civiles y Políticos (PIDCP), según el cual «Toda apología del odio nacional, racial o religioso que constituya incitación a la discriminación, la hostilidad o la violencia estará prohibida por la ley» (Faúndez Ledesma, 2004).

Este punto fue desarrollado también por Bertoni ${ }^{5}$, quien cuestiona si estos discursos «deben estar prohibidas por la ley» como indica el artículo 13.5 en español o si «deben ser consideradas delitos punibles por ley», como se traduciría la versión en inglés "shall be considered as offenses punishable by law»). A partir de esta diferencia semántica, el ex Relator sostiene que el artículo 13.5 establece un tipo especial de las responsabilidades ulteriores previstas en el inciso 2 y no una posibilidad de prohibición de contenidos. Este aporte de Bertoni fue retomado por los sucesivos relatores de la OEA, que entienden que los fallos y opiniones consultivas de la Corte IDH, no admiten restricciones previas (Loretti, 2012, p. 29).

\subsection{La posición de la Corte Interamericana de Derechos Humanos}

Como señalamos anteriormente, el punto de partida para nuestro análisis de la jurisprudencia de la Corte IDH es la falta de sentencias explícitas en la materia. Sin embargo, existen otros fallos y opiniones consultivas relacionados a la censura que servirán de cimiento a nuestra argumentación.

\footnotetext{
${ }^{5}$ RELE-OEA (2004, capítulo 5).
} 


\subsubsection{La Opinión Consultiva 5/85}

Las principales referencias al posicionamiento de la Corte IDH en relación al discurso de odio pueden encontrarse en la Opinión Consultiva (OC) 5/85 sobre la colegiación obligatoria de periodistas. Este documento es tan relevante al interior del SIDH, que recientemente fue objeto de una publicación conmemorando los 30 años de su aparición ${ }^{6}$. En este texto la Corte distinguía dos tipos de restricciones a la libertad de expresión por parte del Estado: La «supresión radical» o censura abierta y los «actos de poder público», que refieren a las formas indirectas de censura por parte del Estado. La única referencia a la afectación de la libertad de expresión por parte de particulares es la «restricción» a la libre expresión generada por la existencia de monopolios informativos ${ }^{7}$.

Gran parte de los casos que ha resuelto desde entonces la Corte IDH se relacionan a casos de «supresión radical» o "restricciones» pero con origen en el poder público. Entre éstos, encontramos sentencias en casos de censura previa ${ }^{8}$, sanciones ulteriores no justificadas bajo los parámetros de la Convención ${ }^{9}$, restricciones indirectas por parte del Estado ${ }^{10}$, reconocimiento del derecho de acceso a la información ${ }^{11}$ y sobre obligación del Estado de proteger el derecho a la libertad de expresión dentro de su jurisdicción y frente a potenciales ataques de agentes no estatales ${ }^{12}$.

En la OC 5/85 la Corte señala que la libertad de expresión tiene una doble vertiente: abarca desde la libertad individual de expresar opiniones hasta el derecho de buscar, recibir y difundir informaciones e ideas de diversa índole. Como consecuencia, a la hora de evaluar la violación del derecho hay que atender tanto los derechos del emisor como el derecho de la sociedad a recibir informaciones e ideas. Esto se debe a que la libertad de expresión tiene una dimensión individual, que comprende el derecho de opinar y de difundir el pensamiento por cualquier medio, y una dimensión social, relacionada con su carácter instrumental para el intercambio de ideas e informaciones y para la comunicación masiva entre los seres humanos. Según

\footnotetext{
${ }^{6}$ Corte Internacional de Derechos Humanos (2017).

${ }^{7}$ El texto de la OC 5/85 denomina «supresión radical» a aquellas situaciones en las que el poder público establece «medios para impedir la libre circulación de información, ideas, opiniones o noticias», por ejemplo, a través de la censura previa, secuestro o prohibición de publicaciones, etc. Por otro lado, denominaba «actos de poder público» a las acciones estatales que implican «una limitación al derecho de buscar, recibir y difundir informaciones e ideas [...] con independencia de si esas restricciones aprovechan o no al gobierno», en referencia distintos medios indirectos de limitar la libertad de expresión por parte del Estado, como el uso arbitrario de la publicidad oficial, la discrecionalidad en la asignación de frecuencias, el abuso de controles oficiales o particulares de papel para periódicos, etc. Junto a estas modalidades de censura directa e indirecta, la OC caracteriza caracterizaba como "restricción», a aquellas limitaciones a la libertad de expresión por la «existencia de monopolios u oligopolios en la propiedad de los medios de comunicación» que generan en la práctica «medios encaminados a impedir la comunicación y la circulación de ideas y opiniones» (OP 5/85, par. 54-56).

${ }^{8}$ Caso Olmedo Bustos y otros v. Chile ("La última tentación de Cristo») de 5 de febrero de 2001.

${ }^{9}$ Caso Herrera Ulloa v. Costa Rica, de 2 de julio de 2004; caso Ricardo Canese v. Paraguay, de 31 de agosto de 2004; caso Palamara Iribarne v. Chile, de 22 de noviembre del 2005; caso Kimel v. Argentina, de 2 de mayo del 2008; caso Tristán Donoso v. Panamá, de 27 de enero 2009; caso Usón Ramírez v. Venezuela, de 20 de noviembre 2009, y caso Fontevecchia D’Amico v. Argentina, de 29 de noviembre de 2011.

10 Caso Ivcher Bronstein v. Perú, de 6 de febrero de 2001; caso Vélez Restrepo y Familiares v. Colombia, de 24 de julio de 2008; Caso Úzcátegui y otros v. Venezuela, de 3 de septiembre del 2012; caso Norín Catriman y otros [dirigentes miembros y autoridades del pueblo indígena Mapuche] v. Chile, de 29 de mayo del 2004, y caso López Lone y otros v. Honduras, de 5 de octubre de 2015.

${ }^{11}$ Caso Claude Reyes y otros v. Chile, de 19 de septiembre de 2006, y caso Gómez Lund y otros v. Brasil, de 24 de noviembre del 2010.

${ }^{12}$ Caso Perozo y otros v. Venezuela, de 28 de enero del 2009; caso Manuel Cepeda Vargas v. Colombia, de 26 de mayo del 2010, y caso Carvajal Carvajal y otros v. Colombia, de 13 de marzo de 2018.
} 
la definición del Tribunal, «estas dos dimensiones deben ser garantizadas de manera simultánea» (OP 5/85, par. 30-33). Si bien el posicionamiento de la Corte se enmarca en otro debate se refería a la necesidad de regular a los monopolios informativos, este reconocimiento de ambas dimensiones de la libertad de expresión y el postulado sobre la garantía simultánea de ambas dimensiones resulta revelador en el marco de nuestro análisis. La pregunta que permanece abierta es cómo debería de posicionarse el Estado en los casos en los que existe un conflicto de interés y en los que esta garantía simultánea de la dimensión individual y la colectiva no resulta posible. En un documento posterior la RELE retoma este argumento: «Una de las principales consecuencias del deber de garantizar simultáneamente ambas dimensiones es que no se puede menoscabar una de ellas invocando como justificación la preservación de la otra» (RELE, 2009, p. 17). Si bien la afirmación de la RELE no ofrece soluciones para los casos de conflicto de interés, resulta de suma relevancia, en tanto cierra la puerta al principio de ponderación predominante en el modelo europeo. Pero si la solución no es menoscabar alguna de las dimensiones o encontrar un «justo medio» por el que ambas dimensiones puedan garantizarse en forma simultánea, aunque sea parcialmente, no queda claro cómo se resolverían estos puntos en tensión.

\subsubsection{La Última Tentación de Cristo}

La postura descrita anteriormente se ve reforzada en un fallo de la Corte IDH, relacionado a la censura judicial a la exhibición cinematográfica de la película $L a$ Última Tentación de Cristo ${ }^{13}$. La CIDH incluyó en su argumentación las siguientes consideraciones sobre el discurso de odio del artículo 13.5:

El artículo 13.5 de la Convención establece la obligación positiva del Estado de evitar la diseminación de información que pueda generar acciones ilegales. Este caso no se enmarca dentro de este supuesto, ya que la versión cinematográfica de Martin Scorsese ha sido definida como obra artística de contenido religioso sin pretensiones propagandísticas. [...] Además, este inciso 5 del artículo 13 debe entenderse dentro del principio establecido en el inciso 1 del mismo artículo, es decir, que «quienes hagan apología del odio religioso deben estar sujetos a responsabilidades ulteriores conforme a la ley» ${ }^{14}$.

En base a estos argumentos la Corte se posicionó en favor de los demandantes y forzó a modificar el artículo 19.12 de la Constitución chilena, que permitía ejercer la censura previa. De este modo, reforzó la interpretación del artículo 13.5 que privilegia los mecanismos de responsabilidades ulteriores sobre los de censura previa (Rosales Roa, 2018, p. 22; Gilas, 2016, p. 105).

\subsection{Los informes de la RELE}

Existen varios documentos elaborados por la RELE de los que puede desprenderse una posición de este organismo en relación a la censura del discurso de odio. El primero de ellos es el Informe del año 2004 de la RELE-OEA mencionado anteriormente, que dedica un capítulo a Las expresiones de odio y la convención americana sobre derechos humanos. En este documento, la Relatoría cuestiona si los discursos de odio "deben estar prohibidas por la ley» como indica el artículo 13.5 en español o si «deben ser consideradas delitos punibles por ley», como se traduciría la versión en inglés «shall be considered as offenses punishable by law») y a partir de esta diferencia semántica se decanta la interpretación a favor de una regulación

\footnotetext{
${ }^{13}$ Caso «La última tentación de Cristo» (Olmedo Bustos y otros vs. Chile).

${ }^{14}$ Caso «La Última Tentación de Cristo» (Olmedo Bustos y otros vs. Chile), par. 69.
} 
basada en un régimen de las responsabilidades ulteriores por sobre un modelo de prohibición de contenidos.

Un segundo documento dedicado explícitamente a la temática es el informe sobre Discurso de odio y la incitación a la violencia contra las personas lesbianas, gays, bisexuales, trans e intersex en América (2015) ${ }^{15}$. El documento sostiene que los Estados: «"deben" adoptar legislación para sancionar la apología del odio que constituya "incitación a la violencia o cualquier otra acción ilegal similar»; «en cambio, según el artículo 13.2 de la Convención Americana, otras expresiones o comentarios intolerantes que no constituyan estrictamente "incitación a la violencia" "pueden" ser sujetos al establecimiento de responsabilidades ulteriores para garantizar los derechos a la dignidad y no discriminación de un grupo particular de la sociedad» (cursivas en el original). De este modo, la Relatoría refuerza la postura a favor del régimen de responsabilidades ulteriores. Para complementar el argumento, el informe sostiene luego:

La CIDH considera necesario enfatizar que la censura del debate sobre asuntos controversiales no atacará las desigualdades estructurales y prejuicios prevalentes que afectan a las personas LGBTI en América. Por el contrario, como principio, en vez de restringirlos, los Estados deben impulsar mecanismos preventivos y educativos y promover debates más amplios y profundos, como una medida para exponer y combatir los estereotipos negativos.

Por último, en un documento de 2017 relacionado a la censura en internet ${ }^{16}$, el ex Relator lleva el argumento contra la censura aún más lejos, cuestionando la validez de normas del SIDH en el contexto americano. El documento reconoce que dentro del SIDH «cuando se está frente a contenidos abiertamente ilícitos o a discursos no resguardados por la libre expresión (como el discurso incitador a la violencia), resultaría admisible la adopción de medidas de bloqueo y filtrado de contenidos específicos». Sin embargo, posteriormente matiza este argumento: «Estas afirmaciones se sostienen en gran medida en las propuestas provenientes del sistema universal. Las notas a pie de página que acompañan esos párrafos lo demuestran. Pero como bien explicó la Corte IDH en la OC-5/85, el Sistema Universal no contiene la prohibición de censura previa que contiene el Art. 13.2 de la $\mathrm{CADH}$ ». Esta clase de interpretaciones abonan a la descripción que se hace frecuente del SIDH como uno de los marcos jurídicos más protectivos de la libertad de expresión.

Un argumento similar se desarrolla en el informe de 2004 citado anteriormente: «Es importante observar que la Corte Interamericana considera que las disposiciones sobre la libertad de expresión de la Convención Americana son más "generosas" que sus contrapartidas de la Convención Europea y el PIDCP» (RELE-OEA, 2004).

La propia Corte ha señalado en la OC 5/85 que una comparación de los tres instrumentos demuestra que «las garantías de la libertad de expresión contenidas en la Convención Americana fueron diseñadas para ser las más generosas y para reducir al mínimo las restricciones a la libre circulación de las ideas» (OC-5/85, par. 50).

Partiendo de esta condición particular de la CADH, el Relator concluye que

Si bien la jurisprudencia de otros sistemas jurídicos puede brindar una orientación valiosa para la interpretación de la Convención Americana y ha sido con frecuencia citada por la Comisión Interamericana y la Corte Interamericana, es importante subrayar los límites de este criterio. No se debe permitir que la aplicación de los

\footnotetext{
15 RELE-OEA (2015).

${ }^{16}$ Bertoni (2017, p. 40).
} 
principios jurídicos de las Naciones Unidas y de la Unión Europea erosionen las libertades fundamentales garantizadas por la Convención Americana [...]. El artículo 13, en su conjunto, también contiene disposiciones concretas que rigen las restricciones a la libertad de expresión y estas disposiciones tienen precedencia frente a las conclusiones que se extraigan de la jurisprudencia de otro sistema jurídico" (RELE-OEA, 2004, par. 34).

\section{Conclusiones}

Para poder analizar los posicionamientos explícitos en relación al discurso de odio en el SIDH, debemos circunscribirnos a los informes de la RELE. En los dos primeros informes (RELE-OEA, 2004 y 2015) el ex Relator Eduardo Bertoni ha ido construyendo una sólida línea argumental, que refuerza una postura a favor del régimen de responsabilidades ulteriores por encima de la regulación de contenidos, siguiendo la línea de la sentencia de la Corte sobre La última tentación de Cristo. En el otro (RELE-OEA, 2017), lleva el argumento en contra la regulación de contenidos aún más lejos, al afirmar que estas medidas admisibles en el marco del SIDH no aplican al contexto americano, ya que el primero no contiene la prohibición de censura previa que contiene el art. 13.2 de la CADH. Si Gargarella (2012) describe al modelo estadounidense como «hiper-protectivo» de la libertad de expresión ${ }^{17}$, necesitaríamos de otra hipérbole para poder describir a la CADH.

Otro punto que merece ser destacado y que se desprende del análisis anterior, es que los órganos del SIDH cuentan con una doctrina más clara y contundente en relación a los casos que la confrontan con problemas liberales clásicos relacionados a la protección de los individuos respecto del Estado y no frente a los abusos de otros individuos. Esto es concordante con lo que plantea Rosales Roa (2018):

La regulación sobre discurso de odio y discurso intolerante con arreglo a los artículos 13.2 y 13.5 de la CADH no sólo no elimina aquella tensión, sino que profundiza el antagonismo entre libertad de expresión e igualdad a partir de un enfoque individualista del fenómeno de la intolerancia que absorbe acríticamente de la Primera Enmienda de Estados Unidos; esto es, de un enfoque que obliga al Estado a abstenerse frente a todo lo que no suponga violencia física.

En un contexto regional e internacional en el que el discurso del odio es un problema creciente, en el que Europa cada vez tiene más fallos del tema y que en Estados Unidos se presiona por una postura más conciliadora entre libertad de expresión y otros valores, derechos y principios, la interpretación abstencionista que propone la RELE podría parecer anacrónica, sobre todo si se contrasta con posiciones como la de Fiss, para quien

Los debates del pasado asumían que el Estado era el enemigo natural de la libertad. Era el Estado el que estaba tratando de silenciar al individuo, y era al Estado al que había que poner límites. Hay una gran dosis de sabiduría en esta concepción, pero se trata de una verdad a medias. Ciertamente el Estado puede ser opresor, pero también puede constituir una fuente de libertad" (Fiss, 1996).

Sin embargo, en el contexto político que se vive en nuestro continente, en el que abundan los casos de acoso judicial a periodistas, cifras alarmantes de

\footnotetext{
17 Como sostiene Gargarella: «La concepción teórica hasta aquí defendida, claramente, viene a confrontar con muchas de las opiniones jurisprudenciales examinadas. Contra ellas, otorga al derecho de la libertad de expresión un estatus especial dentro de la estructura constitucional, y aún dentro de la estructura de derechos. La crítica al gobierno y a los funcionarios públicos, entonces, aparece hiperprotegida dentro de una categoría de derechos ya hiperprotegidos» (Gargarella, 2012, p. 36).
} 
asesinatos de periodistas e impunidad en estos crímenes, uso arbitrario de la pauta de publicidad oficial, manipulación del flujo de información en redes sociales, etc., existen razones sobradas para desconfiar de Estado como fuente de libertad y asumir una postura «hiperprotectora» de la libertad de expresión.

Aun cuando no existen fallos explícitos de la Corte IDH en torno al discurso de odio, en el marco de la OC 5/85 la Corte desarrolló un argumento de importancia crucial a la hora de evaluar su postura respecto a la tensión entre derechos individuales y colectivos, cuando afirma que la libertad de expresión tiene una dimensión individual y una dimensión social y que «estas dos dimensiones deben ser garantizadas de manera simultánea» (OP 5/85, par. 30-33).

En principio, esta afirmación podría dar pie a una interpretación menos tajante de la prohibición de censura, en la que el derecho de los individuos a la libre expresión sea ponderado con otros valores, derechos y principios asociados a la «dimensión social» de la libertad de expresión, como sucede en el modelo europeo de regulación de discursos de odio. Sin embargo, el argumento posterior de la RELE (2009, p. 17) contra la restricción de una de ellas invocando como justificación la preservación de la otra, limita esta interpretación al cerrar la puerta al principio de ponderación predominante en el modelo europeo.

Si no resulta posible dar prioridad a la garantía de un derecho sobre otro en función del contexto, ni es posible sacrificar parcialmente ambas para llegar a un «justo medio», ¿de qué modo se pueden garantizar simultáneamente ambas dimensiones de la libertad de expresión? Desde un punto de vista de la lógica argumental, pareciera que nos encontramos ante un problema sin solución. Sin embargo, no nos encontramos solamente ante un problema jurídico sino también ante un problema político. La respuesta al mismo puede ser jurídica en lo que refiere a la prohibición absoluta de toda forma de censura y política en lo que refiere a generar las condiciones materiales e institucionales para que todas las personas puedan expresarse en el espacio público en condiciones de igualdad y para promover un discurso a favor de la tolerancia, la inclusión y la equidad.

Este parece ser el camino elegido por buena parte de los gobiernos del continente americano. Como señala Bertoni en un estudio sobre la prohibición de la incitación al odio en las Américas, buena parte de los gobiernos de la región han incorporado mecanismos sancionatorios del discurso de odio bajo distintas figuras legales ${ }^{18}$. Sin embargo, los mismos no son aplicados con frecuencia:

Estamos ante declaraciones vinculantes de condena a ciertas conductas que se entienden atentan contra el orden democrático, pero nada más allá. De allí las escasas decisiones que se han encontrado, todas además (salvo los casos estadounidense y argentino) bastante marginales. Y es que la clave histórica bajo la que se lee el artículo 20 del PIDCP (el fenómeno del nazismo), no responde necesariamente a las particularidades socioculturales de los países de la región americana (Bertoni, 2010, p. 19).

\footnotetext{
18 Según el ex Relator en el año 2010 once de los 29 países estudiados en las Américas habían incorporado de manera directa o indirecta la prohibición de los discursos de odio en su codificación penal. Son los casos de: Argentina, Bolivia, Canadá, Costa Rica, El Salvador, Ecuador, Guatemala, Nicaragua, Perú, Santa Lucía y Uruguay. Este patrón normativo se manifiesta con mayor intensidad en los países de Centro (4 de 7) y Sudamérica (5 de 9), en donde, además, se encuentran concentrados la mayor parte de los Estados americanos provenientes de la tradición jurídica continental europea (o del civil law system) (Bertoni, 2010, p. 7).
} 
Paralelamente, el ex Relator observa desde la década de 1990 «una notable apuesta por los mecanismos no sancionatorios, en especial por la generación de políticas públicas y la creación de comisiones o comités en el ámbito gubernamental para su seguimiento» (Bertoni, 2010, p. 19). Bertoni encuentra el origen de esta apuesta por las políticas públicas en la experiencia brasileña, «que progresivamente se ha ido alejando de un modelo sancionatorio hacia mecanismos extrapenales que procuran sensibilizar y capacitar antes que imponer penas de cárcel» (Bertoni, 2010, p. 19).

Más allá de los avances que hubo en las últimas décadas en la formulación de políticas integrales para contrarrestar los discursos de odio, aún queda mucho camino por recorrer. En este sentido, Torres y Taricco consideran que en la región aún es necesario contar con investigaciones sistemáticas y mecanismos de recolección de información, que permitan avanzar en la comprensión del fenómeno y construir respuestas en base a evidencia y a partir de la distinción entre distintos tipos de discursos de odio (Torres y Taricco, 2019, p. 19).

Retomando el debate presentado a comienzos de este artículo, podemos encontrar una formulación teórica de esta postura en el modelo de liberalismo igualitario de Dworkin (1996 y 2000). Este autor propone establecer barreras infranqueables a la intervención estatal en la regulación de los discursos y apuesta simultáneamente por un Estado que contribuya activamente a neutralizar las influencias desmedidas resultantes de fuentes (injustas) de desigualdad económica o de poder social, mediante la distribución de recursos materiales y otras oportunidades. Siguiendo estos principios, y en consonancia con los lineamientos del Sistema Interamericano de Derechos Humanos, es posible generar mecanismos para que la igualdad y la libertad de expresión no sólo sean compatibles, sino que se necesiten mutuamente y contribuyan a la promoción de sociedades libres, tolerantes e incluyentes.

\section{Bibliografía}

Alcácer Guirao, R. (2012). Discurso del odio y discurso político: en defensa de la libertad de los intolerantes. Revista Electrónica de Ciencia Penal y Criminología, núm. 14-02, pp. 02:1-02:32.

Alcácer Guirao, R. (2015). Víctimas y disidentes. El «discurso del odio» en EE. UU. y Europa. Revista Española de Derecho Constitucional, núm. 103, Enero-abril, pp. 45-86.

Alonso, L. y Vázquez, V. (dirs.) (2017). Sobre la libertad de expresión y el discurso del odio. Textos críticos. Sevilla, España: Athenaica.

Bertoni, E. (2010). Estudio sobre la prohibición de la incitación al odio en las Américas. Informe preparado para los talleres organizados por el Alto Comisionado en Derechos Humanos de Naciones Unidas. Recuperado de: https://www.ohchr.org/documents/issues/expression/iccpr/santiago/santiagostud y sp.pdf

Boyle, K. (1992). Overview of a dilemma: Censorship versus racism. En Colliber, S. (Ed.), Striking a balance: Hate speech, freedom of expression and nondiscrimination (pp. 1-8). Londres, Reino Unido: Article 19, International Centre Against Censorship, Human Rights Centre, University of Essex.

Bustos Gisbert, R. (2015). Libertad de expresión y discurso negacionista. En Revenga Sánchez, M. (dir.), Libertad de expresión y discursos del odio (pp. 126-133). Madrid, España: Universidad de Alcalá. 
Collí Ek, V. (2014). Discursos de odio y su defensa en la doctrina constitucional mexicana. Anuario de Derecho Constitucional Latinoamericano, Año XX, pp.79103. Bogotá, Colombia: Fundación Konrad Adenauer.

Collí Ek, V. (2015a). ¿Libertad de expresión o responsabilidad? ¿Cuándo, en el caso de portales sobre noticias, de acuerdo con la Corte Europea de Derechos Humanos?. Revista Cuestiones Constitucionales, núm. 33, Julio-Diciembre, pp. 195-210.

Collí Ek, V. (2015b). La libertad de expresión de portales web de noticias y la protección del anonimato online. Análisis de la reciente doctrina de la Gran Cámara de la Corte Europea de Derechos Humanos en el caso Delfi AS contra Estonia. Revista In Jure Anáhuac Mayab, Año 4, Núm. 7, pp. 28-39.

Comité de Ministros Consejo de Europa [CMCE] (1997), Recomendación No. R (97) 20 del Comité de Ministros a los estados miembros sobre "empleo de discurso de odio".

Dworkin, R. (2000). ¿Entran en conflicto la libertad y la igualdad?. En Barker, P. (comp.), Vivir como iguales. Apología de la Justicia Social (pp. 57-80). Buenos Aires, Argentina: Paidós.

Dworkin, R. (1996). Freedom's Law. The Moral Reading of the American Constitution. Cambridge, Estados Unidos: Harvard University Press.

Esquivel Alonso, Y. (2016). El discurso del odio en la jurisprudencia del Tribunal Europeo de Derechos Humanos. Cuestiones Constitucionales, núm. 35, Diciembre 2016, pp. 3-44.

Faúndez, H. (2004). Los límites a la libertad de expresión. Ciudad de México, México: Universidad Autónoma de México.

Fiss, O. (1996). The Irony of Free Speech. Cambridge, Estados Unidos: Harvard University Press.

Fiss, O. (1997). Libertad de Expresión y estructura social. Ciudad de México, México: Fontamara.

García Santos, M. (2017). El límite entre la libertad de expresión y la incitación al odio: análisis de las sentencias del Tribunal Europeo de Derechos Humanos. Comillas Journal of International Relations, núm. 10, pp. 27-46.

Gargarella, R. (2009). Constitucionalismo y libertad de expresión. En Gargarella, R. (ed.), Teoría y Crítica del Derecho Constitucional (Tomo II, Cap. XXVIII). Buenos Aires, Argentina: Abeledo Perrot.

Gilas, K. (2016). Libertad de expresión en el ámbito electoral en México (a la luz de los estándares internacionales). Ciudad de México, México: Tirant Lo Blanch.

Kaufman, J.C. (2015). Creativity Is Life: A Commentary on the Special Issue. The Journal of Creative Behaviour, núm. 49(3), pp. 233-237.

Loretti, D. (2012). Tensiones entre la libertad de expresión y la protección contra la discriminación: La incidencia de las regulaciones sobre censura previa y el debate sobre el rol del Estado. Democracia y Derechos, Año 1, núm. 1, pp. 15-34.

MacKinnon, C. (1987). Feminism Unmodified: Discourses on Life and Law. Cambridge, Estados Unidos: Harvard University Press.

MacKinnon, C. (1993). Only words. Cambridge, Reino Unido: Cambridge University Press.

Massaro, T. (1991). Equality and freedom of expression. The Hate Speech Dilemma. William and Mary Law Review, núm. 32, pp. 211-265. Recuperado de https://scholarship.law.wm.edu/wmlr/vol32/iss2/3

Matsuda, M. y otros (1993). Words That Wound: Critical Race Theory, Assaultive Speech, and the First Amendment. Boulder, Estados Unidos: Westview Press.

RELE (2015) Violencia contra personas LGBTI. Recuperado de https://www.oas.org/es/cidh/informes/pdfs/ViolenciaPersonasLGBTI.pdf

RELE. (2004) Las expresiones de odio y la convención americana sobre derechos humanos. 
http://www.oas.org/es/cidh/expresion/docs/informes/odio/Expreisones\%20de\%2 0odio\%20Informe\%20Anual\%202004-2.pdf

RELE. (2004). Las expresiones de odio y la convención americana sobre derechos humanos. Recuperado https://www.google.com/url?sa=t\&rct=i\&q=\&esrc=s\&source=web\&cd=1\&ved=2a hUKEwj64MfbsqfoAhVGQq0KHanrBR4QFjAAegQIBRAB\&url=http\%3A\%2F\%2F www.oas.org\%2Fes\%2Fcidh\%2Fexpresion\%2Fshowarticle.asp\%3FartID\%3D44 3\%26IID\%3D2\&usg=AOvVaw1hEdkEdx5hxntq08mgpkKL

RELE. (2015) Informe anual 2015. Recuperado de http://www.oas.org/es/cidh/expresion/docs/informes/anuales/InformeAnual2015 RELE.pdf

RELE.(2009) Marco juridico interamericano sobre el derecho a la libertad de expresión.

Recuperado

de http://www.oas.org/es/cidh/expresion/docs/cd/sistema interamericano de derec hos humanos/index MJIAS.html

Rodríguez Zepeda, J. (2018). El peso de las palabras: libre expresión, no discriminación y discursos de odio. En Rodríguez Zepeda, J. y González Luna, T. dirs.), El prejuicio y la palabra: los derechos a la libre expresión y a la no discriminación en contraste (pp. 27-73). Ciudad de México, México: Consejo Nacional para Prevenir la Discriminación.

Rosales, R. (2018). Liberalismo igualitario, discurso de odio y grupos discriminados: una teoría contra el discurso de odio para la región. Recuperado de https://www.academia.edu/40114792/ Liberalismo igualitario discurso de odio y grupos discriminados una teor\%C3\%ADa contra el discurso de odio pa ra la región ?auto=download

Rosenfeld, M. (2005). El discurso del odio en la jurisprudencia constitucional: análisis comparativo. Pensamiento Cosntitucional, 11, pp. 153-198.

Salazar, P. y Gutiérrez, R. (2008). El derecho a la libertad de expresión frente al derecho a la no discriminación. Ciudad de México, México: Instituto de Investigaciones Jurídicas de la Universidad Nacional Autónoma de MéxicoConsejo Nacional para Prevenir la Discriminación.

Sunstein, Cass R. (1993). Democracy and the problem of free speech. Nueva York, Estados Unidos: The Free Press.

Teruel Lozano, G. (2017). El discurso del odio como límite a la libertad de expresión en el marco del convenio europeo. ReDCE, núm. 27, Enero-Junio de 2017. Recuperado de https://www.ugr.es/ redce/REDCE27/articulos/03 TERUEL.htm

Teruel Lozano, G. (2018). Cuando las palabras generan odio: límites a la libertad de expresión en el ordenamiento constitucional español. Revista Española de Derecho Constitucional, núm. 114, pp. 13-45.

Torres, N. y Taricco, V. (2019). Los discursos de odio como amenaza a los derechos humanos. Buenos Aires, Argentina: Centro de Estudios para la Libertad de Expresión.

Unesco (2015). Combatiendo el Discurso de Odio en Línea [Countering Online Hate Speech], 2015, pp. 10-11.

Valero Heredia, A. (2017). Los discursos del odio. Un estudio jurisprudencial. Revista Española de Derecho Constitucional, núm. 110, pp. 305-333.

Waldron, J. (2012). The Harm in Hate Speech. Cambridge, Estados Unidos: Harvard University Press.

Waldron, J. (2015). Dignity, Rank and Rights. Oxford, Reino Unido: Oxford University Press.

Walker, Samuel (1994). Hate speech. The history of an American controversy. Lincoln, Estados Unidos: University of Nebraska Press. 